\title{
The Effect of Polymer Addition on Base Catalysed Glycerol Oxidation Using Gold and Gold-Palladium Bimetallic Catalysts
}

\author{
Laura Abis $^{1} \cdot$ Nikolaos Dimitritatos $^{1,2} \cdot$ Meenakshisundaram Sankar $^{1} \cdot$ Simon J. Freakley ${ }^{3}$ [D $\cdot$ Graham J. Hutchings $^{1}$
}

Published online: 17 December 2019

(c) The Author(s) 2019

\section{Abstract}

The oxidation of glycerol represents both a viable route to catalytic upgrading of biomass and has become a model reaction for catalytic polyol oxidation. Gold and gold-palladium nanoparticle catalysts prepared by colloidal methods involving polymer additives have been extensively studied. However, the effect of residual polymer at the catalyst surface on reaction pathways has not been decoupled from particle size effects. We show that when using catalysts prepared without polymer stabilisers the addition of either polyvinyl alcohol or polyvinylpyrrolidone to the reaction changes the reaction rate and results in a change in reaction selectivity. We conclude that the polymer additive has a significant effect on the reaction pathway and that these systems should be considered as a metal surface-polymer interface catalytic systems and properties should not be rationalised solely based on nanoparticle size.

\section{Graphic Abstract}

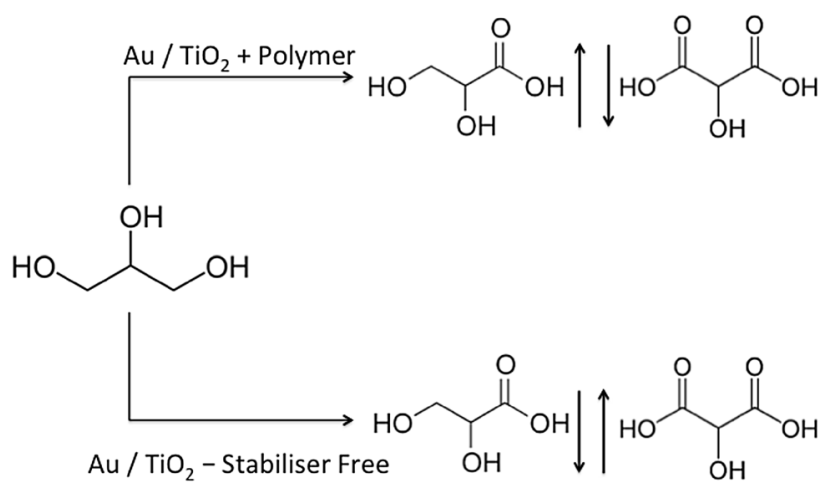

Keywords Glycerol oxidation · Gold · Palladium · Polymer $\cdot$ Colloidal synthesis

Electronic supplementary material The online version of this article (https://doi.org/10.1007/s11244-019-01212-y) contains supplementary material, which is available to authorized users.

Simon J. Freakley

s.freakley@bath.ac.uk

$\bowtie$ Graham J. Hutchings

hutch@cardiff.ac.uk

1 School of Chemistry, Cardiff Catalysis Institute, Cardiff University, Main Building, Park Place, Cardiff CF10 3AT, UK
2 Department of Industrial Chemistry, Alma Mater Studiorum-University of Bologna, Viale Risorgimento, 440136 Bologna, Italy

3 Department of Chemistry, University of Bath, Claverton Down, Bath BA2 7AY, UK 


\section{Introduction}

The selective catalytic oxidation of glycerol and other polyols is considered a promising approach to valorising the by-products of industrial biodiesel production [1]. However, its high degree of functionalisation makes the development of selective catalysts to produce high value products of fundamental importance. Supported metal nanoparticles have been studied extensively: amongst these, Au nanoparticles have been widely investigated since the pioneering studies of Rossi, Prati [2,3] and Hutchings [4-7], who were among the first to demonstrate their higher selectivity and stability [8] compared to $\mathrm{Pt}$ and Pd based catalysts which are more prone to deactivation due to oxidation and leaching under basic conditions $[9,10]$. The problem can be partially overcome by alloying Au with other metals such as $\mathrm{Pd}, \mathrm{Pt}$ and supporting on acidic or basic supports, which improve activity under soluble base-free conditions [11-13]. These catalysts were shown to be very promising in terms of improvement of catalytic stability, activity and selectivity showing higher selectivity to $\mathrm{C}_{3}$ products compared to monometallic analogues [4, 14-17].

A large number of studies have investigated the effect of nanoparticle size across a range of catalyst preparation techniques [18-21]. Generally smaller Au nanoparticles (2-6 nm), with large metal surface area and edge exposure were more active than larger nanoparticles $(10-30 \mathrm{~nm})$, but the latter showed an increased selectivity towards glycerate/glyceric acid [22]. Conversely, smaller nanoparticles led to an increased selectivity towards $\mathrm{C}_{2}$ (mainly glycolate/glycolic acid) and $\mathrm{C}_{1}$ products, as a consequence of the increased hydrogen peroxide production and subsequent $\mathrm{C}-\mathrm{C}$ cleavage, as demonstrated by Davis et al. [21, 23-25].

Sol-immobilisation has been one of the most popular methodologies for the synthesis of catalysts for glycerol oxidation $[2,26]$. It allows mono and bimetallic nanoparticles to be synthesised in solution with controlled size, shape and morphology prior the deposition onto a support $[20,27]$. The main drawback, however, is the presence of stabilising agents such as polymers or surfactants, needed to achieve good control on the nanoparticles size, which could have an influence on the catalytic activity and selectivity [28-30]. Therefore, efforts to assess the influence of the different methodologies for polymer removal without changing the nanoparticles morphology include, heat treatment [31], intensive washing [32] and UV-light irradiation under ozone atmosphere [33]. Given the many drawbacks of the presence of stabiliser, we previously proposed a new synthetic methodology for the preparation of $\mathrm{Au}$ and AuPd nanoparticle catalysts by sol-immobilisation without the addition of stabilisers [27]. The prepared catalysts showed similar catalytic activity with variation in glycerate to tartronate ratio to the traditional PVA stabilised catalysts for glycerol oxidation but showed lager particle size distributions.

This study aims to elucidate similarities and differences in the reaction pathway for these materials and whether these can be correlated to the presence and nature of the residual polymer stabilisers.

\section{Results and Discussion}

A range of $\mathrm{Au}$ and AuPd nanoparticle catalysts supported on $\mathrm{TiO}_{2}$ were synthesized according to previously reported sol immobilisation methodology using polymeric stabilisers, such as, polyvinyl alcohol (PVA) and polyvinylpyrrolidone (PVP). In addition, a material was synthesized by the same methodology in the absence of a polymer stabiliser (denoted as $\mathrm{SF}$-stabiliser free) according to our previously reported method [27]. These materials were tested for glycerol oxidation under basic conditions at $60{ }^{\circ} \mathrm{C}$ under 3 bar $\mathrm{O}_{2}$ and all three monometallic $\mathrm{Au} / \mathrm{TiO}_{2}$ samples showed comparable levels of glycerol conversion (Fig. 1). However, the presence of the polymer during the preparation seems to have an influence on the selectivity towards the major/primary oxidation products, tartronate (TA) and glycerate (GA). Selectivity to TA appeared to be higher on SF samples prepared without polymer, following the trend SF $>$ PVA $>$ PVP, whereas GA followed the opposite trend, in all cases the products seemed to be relatively stable under the reaction conditions. Similarly (Fig. S1) AuPd/TiO 2 prepared with PVA, PVP and without the presence of polymer showed similar activity towards glycerol conversion with a more facile conversion of glyceric acid to tartronate at conversions $<100 \%$ in contrast to monometallic catalysts.

The monometallic Au catalysts prepared with polymer stabiliser and stabiliser free were characterised by transmission electron microscopy (TEM) (Fig. 2) to determine the particle size distribution of the Au nanoparticles. As expected the samples prepared with polymer stabilisers had narrower Au particle size distributions and smaller average Au particle sizes (PVA: $2.7 \pm 0.6 \mathrm{~nm}$; PVP: $3.5 \pm 1 \mathrm{~nm}$, SF: $5.4 \pm 1.6 \mathrm{~nm}$ ). However, this trend in particle size does not correlate with the observed trends in the selectivity of glycerate and tartronate. These results suggest that other factors influence the reaction pathways, specifically the selectivity towards primary products.

The selectivity towards $\mathrm{C}_{3}$ products glycerate (GA) and tratronate (TA) for all the catalysts tested reached $70-80 \%$. Analysis of the distribution of minor oxidation products can also contain important information to identify differing reaction pathways. Minor products comprised oxalate (OXA), 


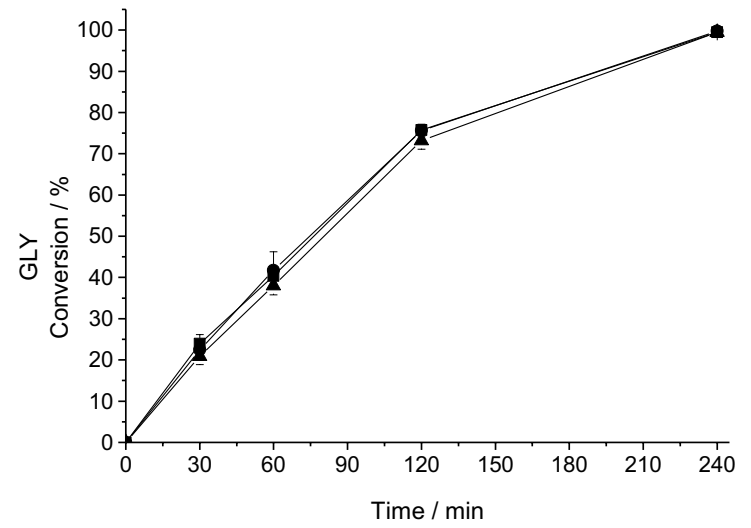

Fig. 1 Comparison of the glycerol oxidation activity for $1 \%$ wt Au/ $\mathrm{TiO}_{2}$ catalysts prepared SF, PVA and PVP. Reaction conditions: glycerol $0.6 \mathrm{M}, \mathrm{NaOH} 1.2 \mathrm{M}, 110 \mathrm{mg}$ catalyst, 3 bar $\mathrm{O}_{2}, 60{ }^{\circ} \mathrm{C}$,

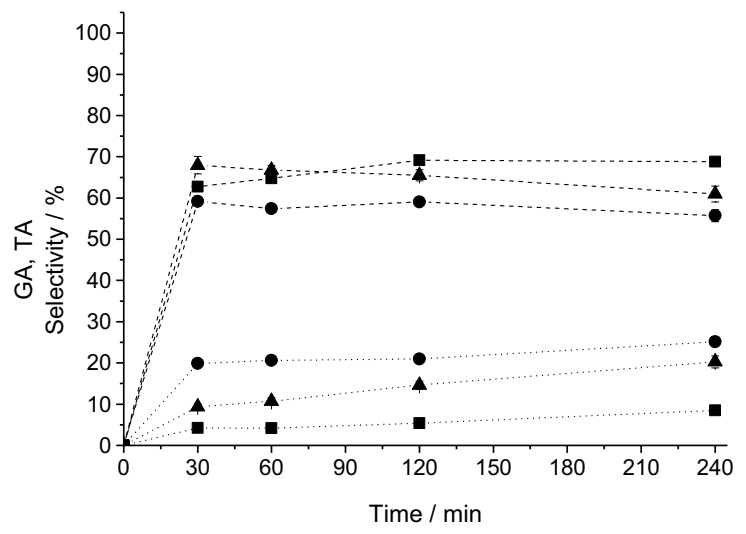

$1200 \mathrm{rpm}, \mathrm{Gly} / \mathrm{Au}=500$, total volume $10 \mathrm{~mL}$. Legend: SF (filled circle), PVA (filled triangle), PVP (filled square); dotted lines-tartronate (TA) selectivity; dashed lines-glycerate (GA) selectivity

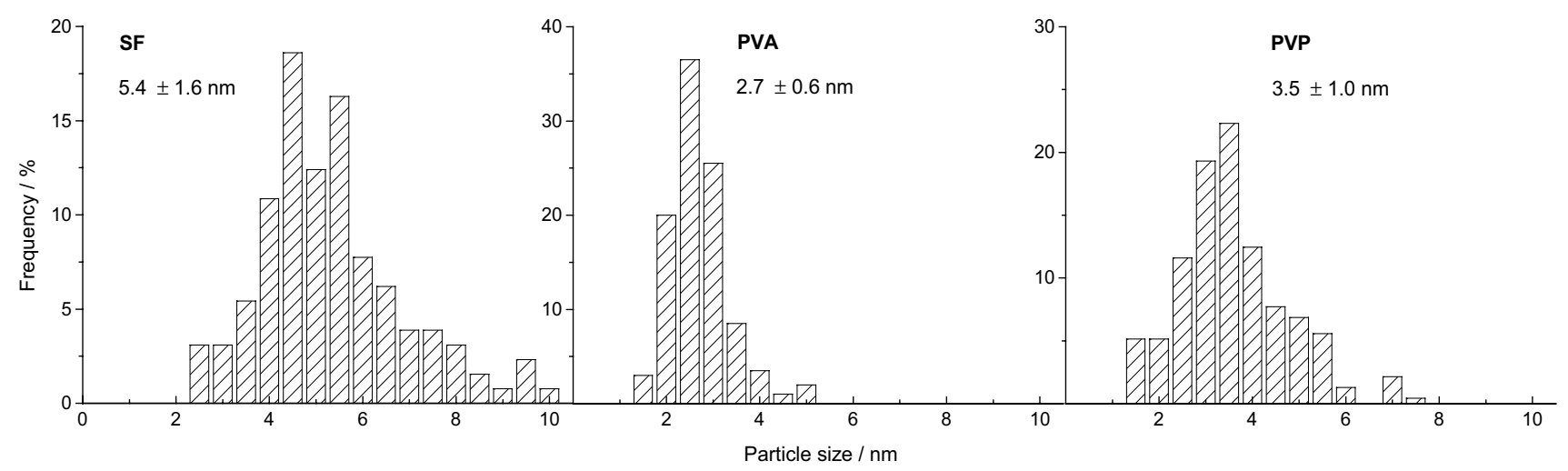

Fig. 2 Particle size distributions derived from bright field TEM images of more than 100 monometallic Au particles prepared stabilizer free, or with PVA and PVP ligands present

lactate (LA), glycolate (GLY), formate (FA), pyruvate (PA) and acetate (ACA) for both the mono and bimetallic catalysts, as displayed in Figs. 3 and 4. In the monometallic case, the catalysts prepared by polymer addition showed higher selectivity towards LA: the highest value observed in the case of PVP suggesting that it is also dependent on the nature of the polymer. Among the minor oxidation products the $\mathrm{SF} 1 \mathrm{wt} \% \mathrm{Au} / \mathrm{TiO}_{2}$ catalyst produced ACA in highest selectivity suggesting that the SF catalyst is less selective to $\mathrm{C}_{3}$ products and could more readily cleave $\mathrm{C}-\mathrm{C}$ bonds of $\mathrm{C}_{3}$ products. This difference shows a different or accelerated reaction pathway due to the absence of the stabiliser or to the larger nanoparticle size resulting from the absence of polymer in the preparation.

Previous studies on glycerol oxidation found that larger nanoparticle size was related to an increase in the selectivity towards $\mathrm{C}_{3}$ products (such as glycerate) $[18,34,35]$, while others observed the same trend with decreasing particle size [36]. There is no general consensus about the size influence on the selectivity of glycerol oxidation in this class of material suggesting that size effects alone are not good descriptors of activity and selectivity $[1,24]$. The TEM derived nanoparticle size of the monometallic Au catalysts (PVA: $2.7 \pm 0.6 \mathrm{~nm}$; PVP: $3.5 \pm 1.0 \mathrm{~nm}$, SF: $5.4 \pm 1.6 \mathrm{~nm}$ ) [37], show the influence of the presence and nature of the polymer stabiliser must be taken into consideration when considering activity and selectivity as no general trend with particle size and performance was observed [34]. The same outcome was not observed in the case of bimetallic samples (Fig. 4), where all three catalysts showed similar values of selectivity to minor products, the bimetallic SF catalyst showed highest selectivity (of minor products) to LA, a similar trend to the PVA and PVP samples suggesting that polymer stabilisers have a larger effect on monometallic Au catalysts which have lower reaction rates than the bimetallic AuPd catalyst.

According to many proposed reaction pathways, TA should be obtained via secondary oxidation of glycerate. We have observed (Fig. 1) that samples prepared in the absence 


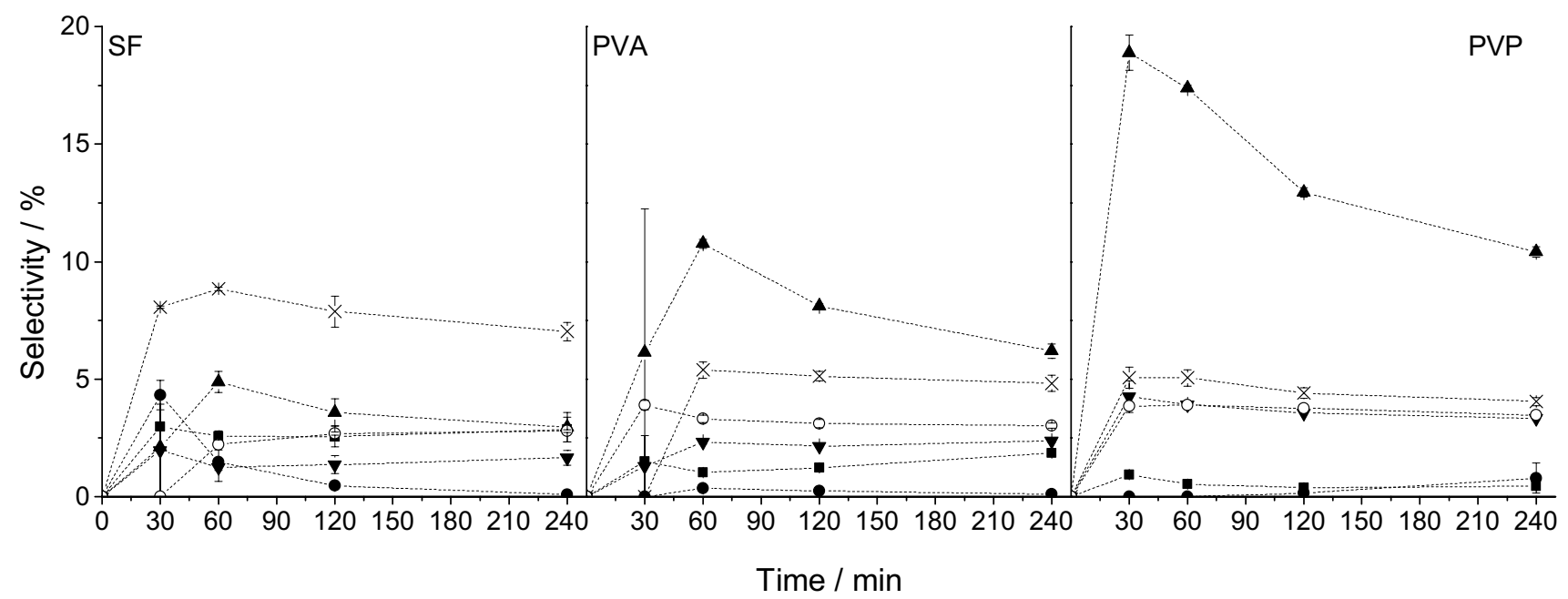

Fig. 3 Time on line selectivity profile to minor oxidation products for the monometallic catalysts synthesized SF, PVA and PVP. Legend: Filled circle Oxalate (OXA), filled triangle Lactate (LA), open circle
Glycolate (GLYA), filled circle Pyruvate (PA), inverted filled triangle Formate (FA), x Acetate (ACA)

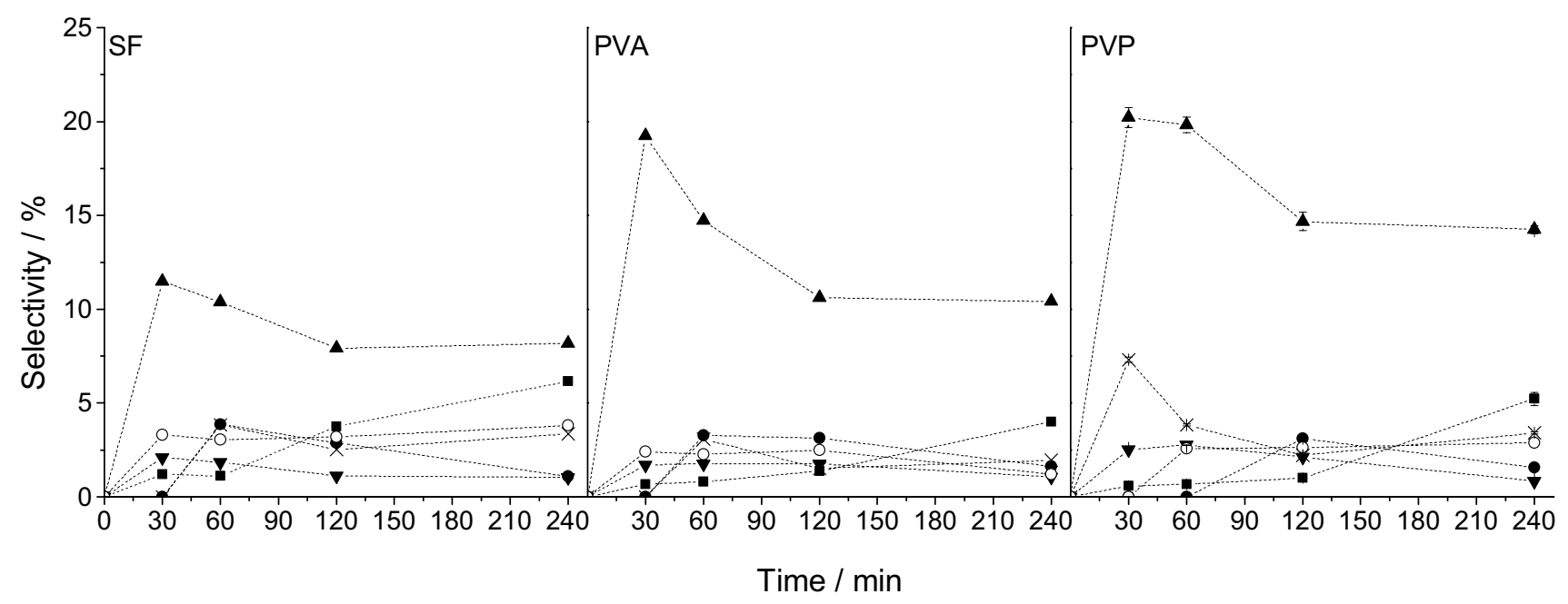

Fig. 4 Time on line selectivity profile to minor oxidation products for the bimetallic catalysts synthesized SF, PVA and PVP. Legend: Filled circle Oxalate (OXA), filled triangle Lactate (LA), open circle Glyco-

of stabiliser have a significantly higher selectivity to TA (1 wt $\% \mathrm{Au} / \mathrm{TiO}_{2}$ (SF) 20\% vs $1 \mathrm{wt} \% \mathrm{Au} / \mathrm{TiO}_{2}$ (PVA) 10\%). To further understand if the presence of the polymer additives effects the reaction pathways, primarily towards the primary products GA and TA, reactions were carried out at low conversion and also using glycerate as a starting material. Experiments using GA as starting material were performed on the monometallic SF and on the bimetallic SF and PVA catalysts. Figure 5 presents the GA conversion profile and late (GLYA), filled circle Pyruvate (PA), inverted filled triangle Formate (FA), x Acetate (ACA)

the relative selectivity to products as a function of time for the monometallic sample prepared SF.

These experiments show that GA oxidation was much slower (Table 1) than glycerol oxidation using the same catalyst: for the monometallic $1 \mathrm{wt} \% \mathrm{Au} / \mathrm{TiO}_{2}(\mathrm{SF})$ after $4 \mathrm{~h}$ reaction glycerol conversion reached $100 \%$, whereas GA conversion reached only $30 \%$ with the major product being TA. Glycolate (GLYA) is also produced at higher amounts from the beginning, in addition to oxalate (OXA) and small amounts of formate (FA). 


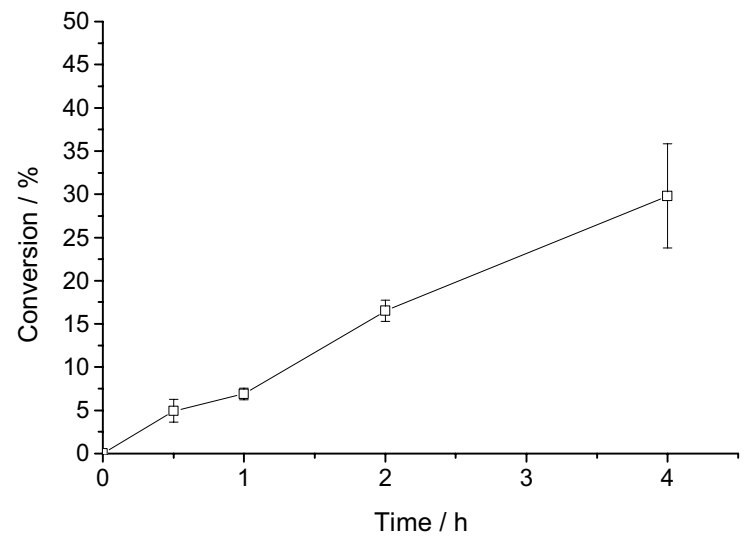

Fig. 5 Glyceric acid oxidation conversion and selectivity based on liquid products for the $1 \% \mathrm{wt} \mathrm{Au} / \mathrm{TiO}_{2}-\mathrm{SF}$ catalyst. Reaction conditions: $110 \mathrm{mg}$ catalyst, $60{ }^{\circ} \mathrm{C}, 3$ bar $\mathrm{O}_{2}, 1200 \mathrm{rpm}, \mathrm{GA} /$ $\operatorname{metal}(\mathrm{s})=500: 1(\mathrm{~mol}), \mathrm{NaOH} / \mathrm{GA}=2: 1(\mathrm{~mol})$, total volume $10 \mathrm{~mL}$.

Table 1 Reaction rates ([M]/ $\left.\mathrm{g}_{\text {cat }} \bullet \mathrm{h}\right)$ calculated for the glycerol (GLY) and glyceric acid (GA) oxidation reactions

\begin{tabular}{lll}
\hline Catalyst & $\begin{array}{l}\text { Rate of } \\
\text { substrate } \\
\text { depletion/ } \\
{[\mathrm{M}] / \mathrm{g}_{\text {cat }} \text { h }}\end{array}$ \\
\cline { 2 - 3 } & $\mathrm{GA}$ & $\mathrm{GLY}$ \\
\hline $\mathrm{Au} / \mathrm{TiO}_{2}-\mathrm{SF}$ & 0.18 & 0.57 \\
$\mathrm{AuPd} / \mathrm{TiO}_{2}-\mathrm{PVA}$ & 0.16 & 0.54 \\
$\mathrm{AuPd} / \mathrm{TiO}_{2}-\mathrm{SF}$ & 0.25 & 0.48 \\
\hline
\end{tabular}

This might indicate that the relative stability of GA and TA during the glycerol oxidation reaction is due either to lower relative reaction rates or to competitive adsorption of glycerol and GA. In a similar experiment performed by Ketchie et al. it was proposed that the lower reaction rate observed for GA oxidation is due to the difficulty in generating the alkoxide, which represents the starting point of the oxidation process [24]. The deprotonation of the alcohol group of the GA is disfavoured because of the presence of the carboxylic acid group. Similar trends, even though less pronounced, can be observed in the case of the bimetallic catalysts prepared SF and PVA (Fig. S2). The bimetallic samples reached higher conversion than the monometallic SF, reaching $45 \%$ and $30 \%$ GA conversion respectively for the SF and PVA catalysts after $4 \mathrm{~h}$ reaction. These results are consistent with the results observed during glycerol oxidation, where further GA oxidation did clearly occur when $100 \%$ glycerol conversion was reached, with the $1 \% \mathrm{wt}$ $\mathrm{AuPd} / \mathrm{TiO}_{2}-\mathrm{SF}$ catalyst having a higher GA oxidation activity than the $1 \%$ wt $\mathrm{AuPd} / \mathrm{TiO}_{2}$-PVA but does not explain the presence of TA when glycerol conversion is less than $100 \%$. During GA oxidation, the main product is TA, nevertheless, comparing the oxidation rates of glycerol and GA to the

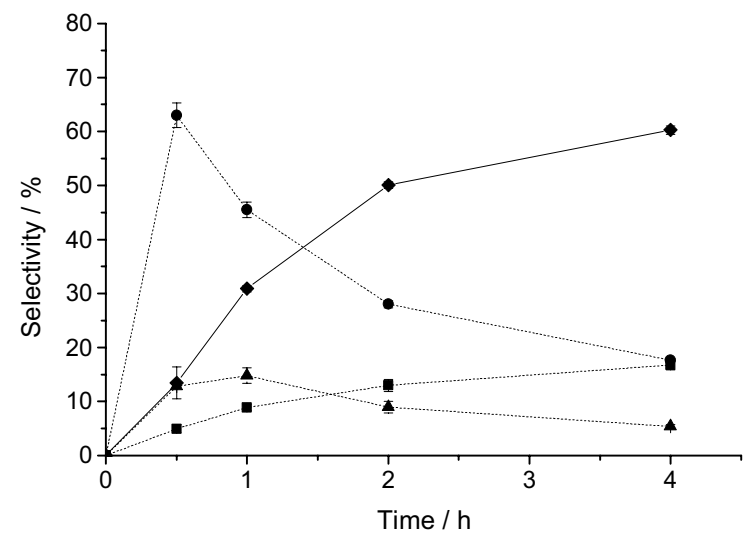

Legend: Open square GA, filled diamond TA (bold line); filled circle Glycolate (GLYA), filled square Oxalate (OXA), filled triangle Formate (FA) (dotted lines)

TA selectivity (or yield) the latter cannot be an exclusive product from GA oxidation during glycerol oxidation. Many reaction schemes show TA as a secondary oxidation product from the GA. However, the results obtained in this experiment, together with those obtained from glycerol oxidation, suggest that TA could be a primary product in addition to being a secondary oxidation product. Evidence of this was also reported in a reaction modelling study by Demirel et al. using gold catalysts [38]. Moreover, it is clear from the glycerol oxidation experiments that the GA conversion to TA only starts when the glycerol has been consumed on monometallic samples.

To further investigate the reaction pathway, the same samples were tested at short reaction times (5-20 min) to keep conversion low (10-15\%). The results obtained for the $1 \%$ wt $\mathrm{Au} / \mathrm{TiO}_{2}$ catalyst prepared SF show that both TA and $\mathrm{GA}$ are produced from the start of the reaction. After $5 \mathrm{~min}$ of reaction, the selectivity towards TA reaches $28 \%$, and is stable throughout the reaction. This result supports the hypothesis that TA can be produced as a primary reaction product and not only through the subsequent oxidation of GA and that higher amounts of TA observed for the SF catalysts are not a result of faster over oxidation of GA (Fig. 6).

Results for GA oxidation using the bimetallic samples prepared SF and with PVA at iso-conversion (Table 2) after 10 min of reaction, show that the selectivity to TA is almost the double for the SF sample compared to the PVA despite the samples showing similar particle size and glycerol conversion activity suggesting the production of higher amounts of TA as a primary product in catalysts prepared without polymer stabiliser.

The results obtained from these experiments using mono and bimetallic catalysts suggest that the absence of the polymer seems to affect the glycerol oxidation pathways and 


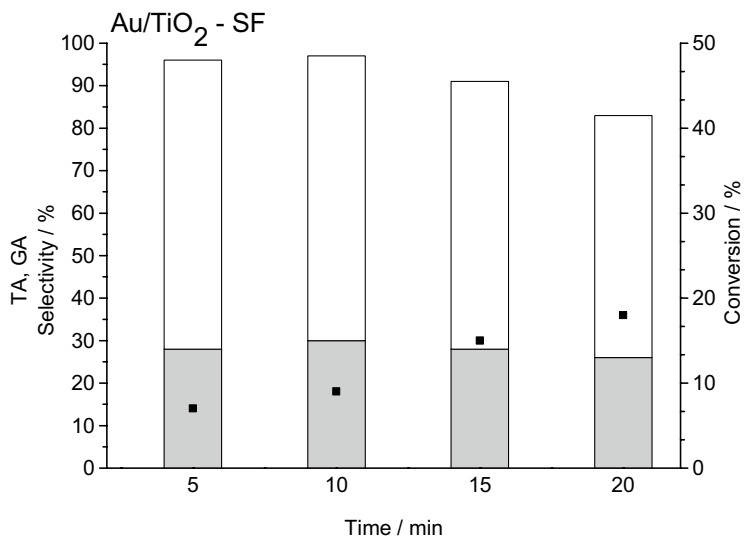

Fig. 6 Glycerol oxidation on $1 \%$ wt $\mathrm{Au} / \mathrm{TiO}_{2}$ prepared SF. Reaction conditions: $110 \mathrm{mg}$ catalyst, $60{ }^{\circ} \mathrm{C}, 3$ bar $\mathrm{O}_{2}, 1200 \mathrm{rpm}, \mathrm{GA} /$ $\operatorname{metal}(\mathrm{s})=500: 1(\mathrm{~mol}), \mathrm{NaOH} / \mathrm{GA}=2: 1(\mathrm{~mol})$, total volume $10 \mathrm{~mL}$. Legend: Grey filled square bars-TA Selectivity, open square barsGA Selectivity, black filled square Glycerol Conversion

Table 2 GA/TA ratio at iso-conversion for the mono and bimetallic catalysts prepared SF and PVA

\begin{tabular}{|c|c|c|c|}
\hline Catalyst & Time/min & Conversion/\% & GA/TA \\
\hline $\mathrm{AuPd} / \mathrm{TiO}_{2}-\mathrm{SF}$ & 10 & 20 & 4 \\
\hline $\mathrm{AuPd} / \mathrm{TiO}_{2}-\mathrm{PVA}$ & 10 & 19 & 14 \\
\hline
\end{tabular}

can drive the selectivity to TA at very early stages of the reaction. To investigate if the observed results were directly related to the presence of polymer on the catalyst surface aliquots of PVA and PVP solutions $(0.1 \mathrm{~g} / 10 \mathrm{~mL})$ were added during glycerol oxidation experiments using the $1 \%$

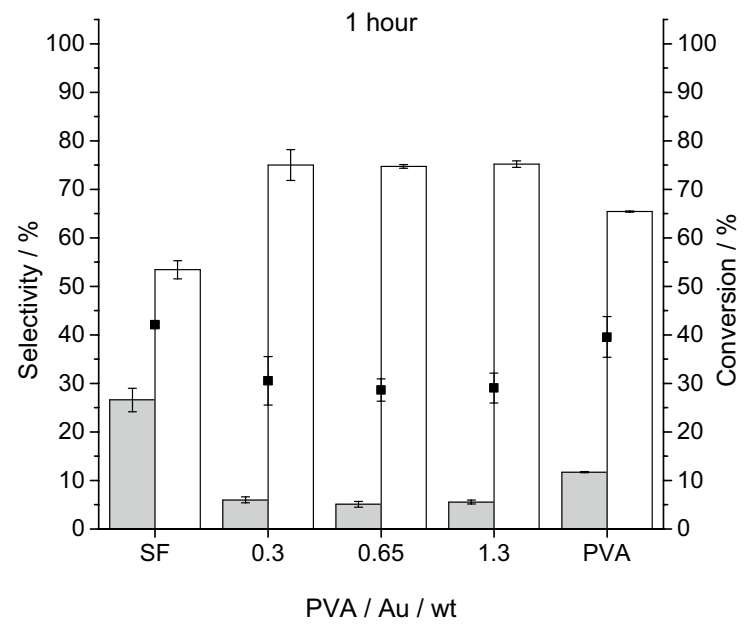

Fig. 7 Glycerol conversion and selectivity after $1 \mathrm{~h}$ and $4 \mathrm{~h}$ reaction for the $1 \%$ wt $\mathrm{Au} / \mathrm{TiO}_{2}-\mathrm{SF}$ in presence of different aliquots of PVA, compared with the $1 \%$ wt $\mathrm{Au} / \mathrm{TiO}_{2}-\mathrm{SF}$ and $1 \%$ wt $\mathrm{Au} / \mathrm{TiO}_{2}-\mathrm{PVA}$. Reaction conditions: $110 \mathrm{mg}$ catalyst, $60{ }^{\circ} \mathrm{C}, 3$ bar $\mathrm{O}_{2}, 1200 \mathrm{rpm}$, wt $\mathrm{Au} / \mathrm{TiO}_{2}-\mathrm{SF}$ catalyst which had been prepared in the absence of polymer. The aim was to obtain more information about the influence of the polymers during the reaction and whether and how they affect the conversion rate and drive the selectivity.

Figure 7 shows the comparison of catalytic activity after 1 and $4 \mathrm{~h}$ reactions for the $1 \% \mathrm{wt} \mathrm{Au} / \mathrm{TiO}_{2}$ catalysts prepared SF and with PVA and the SF sample in presence of aliquots of PVA $(0.1 \mathrm{~g} / 10 \mathrm{~mL})$ corresponding to selected PVA/Au mass ratios typically added to catalyst preparations $(0.3,0.65$ and 1.3). After $1 \mathrm{~h}$ reaction, the presence of PVA reduces the glycerol conversion of the catalyst prepared without stabiliser by about $10 \%$ with respect to the two extremes. The extent to which the PVA is affecting the conversion seems to be independent from its amount, which could suggest saturation of absorption at relatively low polymer amounts. A key observation is that on addition of the even low amounts of PVA the selectivity to TA is significantly reduced in favour of GA-confirming that the presence of polymer can change reaction selectivity-in this case preventing the formation of tartronic acid in favour of glyceric acid explaining the enhanced selectivity towards TA in catalysts prepared without the addition of polymers.

Figure 8 reports analogous experiments carried out using different amounts of PVP, after $1 \mathrm{~h}$ and $4 \mathrm{~h}$ reaction compared to the two "extreme" cases. In this case, the PVP seems not to have a large effect on the conversion after $1 \mathrm{~h}$, which reaches $\sim 40 \%$ for all samples. However, it does have a marked effect on the selectivity, with values for TA and GA very similar to those obtained when the $\mathrm{Au} / \mathrm{TiO}_{2}$ PVP catalyst. The presence of the stabilising agent seems to drive the selectivity to GA rather than to TA. This can be

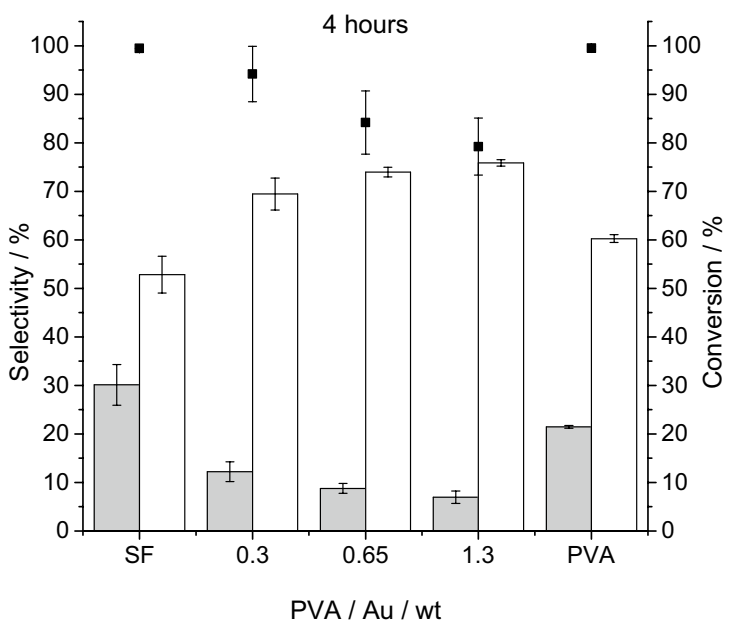

$\mathrm{GA} / \mathrm{metal}=500: 1(\mathrm{~mol}), \mathrm{NaOH} / \mathrm{GA}=2: 1(\mathrm{~mol})$, total volume $10 \mathrm{~mL}$. Legend: Large filled square TA, open square GA, small filled square Glycerol 


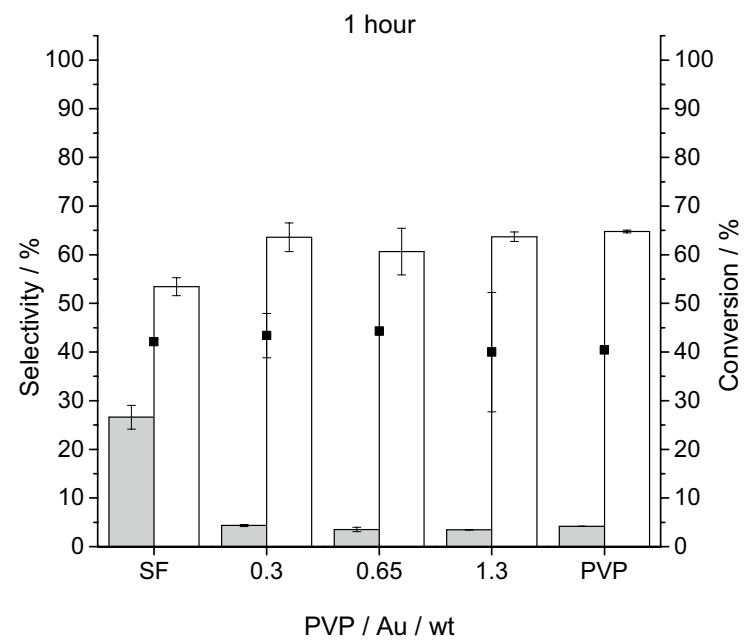

Fig. 8 Glycerol conversion and selectivity after $1 \mathrm{~h}$ and $4 \mathrm{~h}$ reaction for the $1 \%$ wt $\mathrm{Au} / \mathrm{TiO}_{2}$-SF in presence of different aliquots of PVP, compared with the $1 \%$ wt $\mathrm{Au} / \mathrm{TiO}_{2}-\mathrm{SF}$ and $1 \%$ wt $\mathrm{Au} / \mathrm{TiO}_{2}-\mathrm{PVP}$. Reaction conditions: $110 \mathrm{mg}$ catalyst, $60{ }^{\circ} \mathrm{C}, 3$ bar $\mathrm{O}_{2}, 1200 \mathrm{rpm}$,

explained with the hypothesis that the polymers are covering the nanoparticle and blocking specific surface sites, favouring the end-on absorption and oxidation of glycerol to GA rather than allowing the molecules to adsorb side-on which could result in oxidation at both terminal groups. The same trend is observed after $4 \mathrm{~h}$ reaction: by contrast with the PVA addition, the PVP does not have any effect on the conversion. Moreover, selectivity towards TA and GA seems to be stable over time independent of the stabiliser amount, suggesting that either the PVP is not competing with glycerol for the active sites on the catalyst, or its presence is slowing GA oxidation.

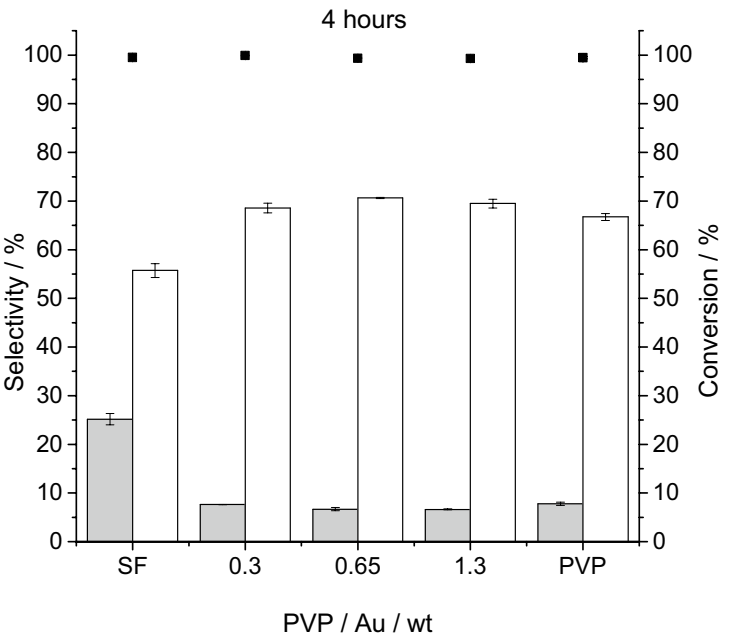

$\mathrm{GA} / \mathrm{metal}=500: 1(\mathrm{~mol}), \mathrm{NaOH} / \mathrm{GA}=2: 1(\mathrm{~mol})$, total volume $10 \mathrm{~mL}$. Legend: Grey filled square bars-TA Selectivity, open square barsGA Selectivity, small filled square Glycerol Conversion

On the basis of the results obtained from the aforementioned experiments Scheme 1 is proposed as a slight revision to the reaction schemes that consider tartronic acid only as sequential oxidation product. The scheme accounts for the primary nature of the TA and GA, and for the over-oxidation of the latter due to the presence of the $\mathrm{H}_{2} \mathrm{O}_{2}$ or of the faster rate of $\mathrm{O}_{2}$ dissociation. The former is also responsible of the $\mathrm{C}-\mathrm{C}$ cleavage of the molecules, leading to higher selectivity to $\mathrm{C}_{2}$ products.
Scheme 1 Proposed reaction mechanism for glycerol oxidation on mono and bimetallic catalysts prepared SF, PVA and PVP<smiles>OCC(O)CO</smiles>
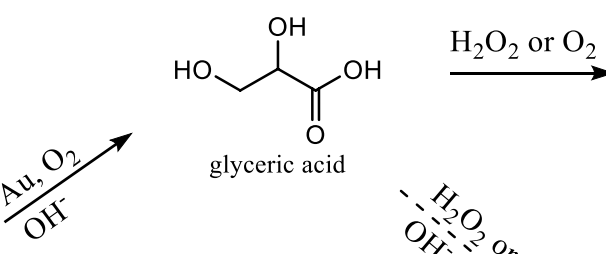

glyceric acid

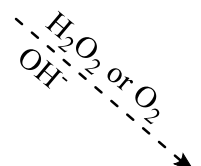<smiles>O=C(O)C(O)C(=O)O</smiles><smiles>CC(O)C(=O)O</smiles>

glycolic acid

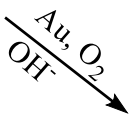

tartronic acid<smiles>O=C(O)C(O)C(=O)O</smiles>

tartronic acid

HO

acetic acid

$\overbrace{\text { formic acid }}^{\text {II }}$<smiles>O=C(O)C(=O)O</smiles>

oxalic acid 


\section{Conclusions}

We have investigated the catalytic oxidation pathways of monometallic and bimetallic catalysts prepared by solimmobilisation via SF, PVA and PVP (typical stabilisers for the synthesis of colloidal metal nanoparticles) and rationalised the results with the presence and nature of residual polymer stabiliser. It can be concluded that different oxidation pathways occur on the SF and PVA modified Au surfaces. Polymer addition studies on SF catalysts evidenced that the PVA influences both the selectivity and the conversion of glycerol oxidation. Conversely, PVP addition influenced the selectivity but not the conversion, independent of the amount. Both these results suggest a different oxidation pathway in presence of polymer. We conclude that the polymer additive has a significant effect on the reaction pathway and that these systems should be considered as a metal surface-polymer catalytic system and properties should not be rationalised solely based on nanoparticle properties such as nanoparticle size. We envisage that these results could form the basis for extensive further study into the nature and design of these metal-polymer interfaces.

\section{Experimental}

\subsection{Catalyst Preparation}

Monometallic (1\% wt $\left.\mathrm{Au} / \mathrm{TiO}_{2}\right)$ and bimetallic (1\% wt $\mathrm{Au}-\mathrm{Pd} / \mathrm{TiO}_{2}$ (molar ratio Au:Pd 1:1)) samples were prepared by sol-immobilisation using PVA and PVP as stabilizing polymer ligands, as well as without any addition of stabilizer (the latter being denoted SF). In a typical synthesis of $1 \mathrm{~g}$ of monometallic sample, an aqueous solution of $\mathrm{HAuCl}_{4} \cdot 3 \mathrm{H}_{2} \mathrm{O}(0.8 \mathrm{~mL}, 12.5 \mathrm{mg} \mathrm{Au} / \mathrm{mL}$ Sigma Aldrich, $\geq 49.0 \%$ ) was added to $400 \mathrm{~mL}$ of deionised water under vigorous stirring conditions, followed by the addition of a polymer stabilizer ( This was either a $1 \mathrm{wt} \%$ aqueous solution of PVA (average molecular weight $\mathrm{MW}=9000-10,000 \mathrm{~g} \mathrm{~mol}^{-1}, 80 \%$ hydrolysed), or a $1 \mathrm{wt} \%$ aqueous solution of PVP (Sigma Aldrich, average molecular weight $\mathrm{MW}=10,000 \mathrm{~g} \mathrm{~mol}^{-1}$ ). Subsequently, a $0.1 \mathrm{M}$ freshly prepared solution of $\mathrm{NaBH}_{4}$ ( $\geq 99.99 \%$, Aldrich) was added $(\mathrm{mol} \mathrm{NaBH} 4 / \mathrm{mol} \mathrm{Au}=5)$ to form a red sol. After $30 \mathrm{~min}$ of sol generation, the colloid was immobilised by adding $0.99 \mathrm{~g}$ of $\mathrm{TiO}_{2}(\mathrm{P} 25$ Aeroxide ${ }^{\circledR}$, Evonik) and 8 drops of concentrated $\mathrm{H}_{2} \mathrm{SO}_{4}$. After $1 \mathrm{~h}$ of continuous stirring, the slurry was filtered, the catalyst washed thoroughly with deionised water and dried at $110{ }^{\circ} \mathrm{C}$ for $16 \mathrm{~h}$. Syntheses for the bimetallic
$\mathrm{Au}-\mathrm{Pd}$ sample proceeded in the same way, but with the further addition of $\mathrm{PdCl}_{2}$ (Sigma Aldrich, Reagent Plus ${ }^{\circledR}$ $99 \%$ ) in aqueous solution ( $6 \mathrm{mg} \mathrm{Pd} / \mathrm{mL})$. In this case, the stabilizer-to-metals ratio was $1.2(\mathrm{wt} / \mathrm{wt})$. The immobilisation steps were carried out in the same manner as previously described. For the stabilizer free (SF) variants, both monometallic and bimetallic analogues were prepared as described above but the addition of stabilizer to the preparation was omitted. The SF sample was immobilised on $\mathrm{TiO}_{2}$ after $30 \mathrm{~min}$ of sol generation. It was observed that the SF colloids start to collapse between 24 and $36 \mathrm{~h}$ after reduction.

\subsection{Glycerol Oxidation}

Glycerol oxidation under basic conditions was performed in a glass reactor (Colaver $\left.{ }^{\circledR}\right)$ positioned in a thermostatically controlled oil bath at $60^{\circ} \mathrm{C}$ and at 3 bar $\mathrm{O} 2$ pressure, under continuous stirring (1200 rpm). Glycerol $(5 \mathrm{~mL}, 0.6 \mathrm{M}$, Sigma Aldrich, anhydrous, $>99.5 \%)$ and $\mathrm{NaOH}(5 \mathrm{~mL}$, 1.2 M, Sigma Aldrich BioXtra $>98 \%$, pellets, anhydrous) were added to the reactor to give a total reaction volume of $10 \mathrm{~mL}$. The glycerol/metal(s) mole ratio was 500:1. The total reaction time employed was $4 \mathrm{~h}$, with sampling performed after 30, 60, 120 and $240 \mathrm{~min}$ of reaction. Samples were quenched and diluted 1:10 in deionised water before analysis by HPLC. Product analysis was carried out using an Agilent 1260 Infinity HPLC with a Metacarb 67H column with a $0.1 \% \mathrm{wt}$ solution of phosphoric acid as mobile phase. Identical conditions were used for the glyceric acid oxidation tests.

\subsubsection{Polymer Influence}

Experiments to investigate the effect of polymer presence (PVA and PVP) were performed using the monometallic SF sample in the presence of PVA or PVP in defined weight ratios with respect to the Au mass $(0.3,0.65,1.3)$, starting from solutions $0.1 \mathrm{~g} / 10 \mathrm{~mL}$. Experiments were carried out at the same conditions as standard glycerol oxidation. Each reactor was charged with the $\mathrm{Au} / \mathrm{TiO}_{2} \mathrm{SF}$ catalyst, glycerol and $\mathrm{NaOH}$ and a certain aliquots of PVA or PVP solution, correspondent to stabiliser/Au (weight ratio) $0.325,0.65$ and 1.3 respectively. The required amount of PVA and PVP solutions $(0.1 \mathrm{~g} / 10 \mathrm{~mL})$ were $38.4 \mu \mathrm{L}, 76.8 \mu \mathrm{L}$ and $0.154 \mathrm{~mL}$ respectively. The weight ratios were determined considering stabiliser/Au ratio 0.65 which is used in the standard catalyst synthesis, with 0.325 and 1.3 being respectively the half and the double of this quantity.

\subsection{Catalyst Characterisation}

Transmission Electron Microscopy (TEM) was performed using a JEOL 2100 microscope with a LaB6 filament 
operating at $200 \mathrm{kV}$. Samples were prepared by dispersing the powder catalyst in ethanol and allowing a drop of the suspension to evaporate on a lacey carbon film supported over a 300 mesh copper TEM grid. Scanning Transmission Electron Microscopy (STEM) was carried out using an aberration corrected JEM ARM-200CF microscope operating at $200 \mathrm{kV}$. This instrument was also equipped with a JEOL Centurio silicon drift detector for X-ray energy dispersive spectroscopy (XEDS). Particle size distributions were determined by measuring 100 particles per sample using imageJ software.

Acknowledgements This work is supported by Cardiff University and the MAXNET Energy research consortium of the Max Planck Society and we thank the Cardiff University Electron Microscopy Facility for instrument access.

\section{Compliance with Ethical Standards}

Conflict of interest The authors declare no financial conflict of interest.

Open Access This article is licensed under a Creative Commons Attribution 4.0 International License, which permits use, sharing, adaptation, distribution and reproduction in any medium or format, as long as you give appropriate credit to the original author(s) and the source, provide a link to the Creative Commons licence, and indicate if changes were made. The images or other third party material in this article are included in the article's Creative Commons licence, unless indicated otherwise in a credit line to the material. If material is not included in the article's Creative Commons licence and your intended use is not permitted by statutory regulation or exceeds the permitted use, you will need to obtain permission directly from the copyright holder. To view a copy of this licence, visit https://creativecommons.org/licenses/by/4.0/.

\section{References}

1. Katryniok B, Kimura H, Skrzynska E, Girardon JS, Fongarland P, Capron M, Ducoulombier R, Mimura N, Paul S, Dumeignil F (2011) Green Chem 13:1960-1979

2. Porta F, Prati L, Rossi M, Coluccia S, Martra G (2000) Catal Today 61:165-172

3. Biella S, Castiglioni GL, Fumagalli C, Prati L, Rossi M (2002) Catal Today 72:43-49

4. Carrettin S, McMorn P, Johnston P, Griffin K, Hutchings GJ (2002) Chem Commun 7:696-697

5. Carrettin S, McMorn P, Johnston P, Griffin K, Kiely CJ, Hutchings GJ (2003) Phys Chem Chem Phys 5:1329-1336

6. Carrettin S, McMorn P, Johnston P, Griffin K, Kiely CJ, Attard GA, Hutchings GJ (2004) Top Catal 27:131-136

7. Enache DI, Edwards JK, Landon P, Solsona-Espriu B, Carley AF, Herzing AA, Watanabe M, Kiely CJ, Knight D, Hutchings GJ (2006) Science 311:362-365

8. Prati L, Rossi M (1998) J Catal 176:552-560

9. Porta F, Prati L (2004) J Catal 224:397-403

10. Besson M, Gallezot P (2000) Catal Today 57:127-141

11. Villa A, Dimitratos N, Chan-Thaw CE, Hammond C, Prati L, Hutchings GJ (2015) Acc Chem Res 48:1403-1412

12. Villa A, Veith GM, Prati L (2010) Angew Chem 49:4499-4502
13. Villa A, Campisi S, Mohammed KMH, Dimitratos N, Vindigni F, Manzoli M, Jones W, Bowker M, Hutchings GJ, Prati L (2015) Catal Sci Technol 5:1126-1132

14. Brett GL, He Q, Hammond C, Miedziak PJ, Dimitratos N, Sankar M, Herzing AA, Conte M, Lopez-Sanchez JA, Kiely CJ, Knight DW, Taylor SH, Hutchings GJ (2011) Angew Chem 50:10136-10139

15. Kondrat SA, Miedziak PJ, Douthwaite M, Brett GL, Davies TE, Morgan DJ, Edwards JK, Knight DW, Kiely CJ, Taylor SH, Hutchings GJ (2014) ChemSusChem 7:1326-1334

16. Villa A, Campione C, Prati L (2007) Catal Lett 115:133-136

17. Dimitratos N, Lopez-Sanchez JA, Anthonykutty JM, Brett G, Carley AF, Tiruvalam RC, Herzing AA, Kiely CJ, Knight DW, Hutchings GJ (2009) Phys Chem Chem Phys 11:4952-4961

18. Dimitratos N, Lopez-Sanchez JA, Lennon D, Porta F, Prati L, Villa A (2006) Catal Lett 108:147-153

19. Rogers SM, Catlow CRA, Chan-Thaw CE, Gianolio D, Gibson EK, Gould AL, Jian N, Logsdail AJ, Palmer RE, Prati L, Dimitratos N, Villa A, Wells PP (2015) ACS Catal 5:4377-4384

20. Bianchi CL, Porta F, Prati L, Rossi M (2000) Top Catal 13:231-236

21. Ketchie W, Fang Y, Wong M, Murayama M, Davis R (2007) J Catal 250:94-101

22. Katryniok B, Kimura H, Skrzyńska E, Girardon J-S, Fongarland P, Capron M, Ducoulombier R, Mimura N, Paul S, Dumeignil F (1960) Green Chem 2011:13

23. Davis SE, Ide MS, Davis RJ (2013) Green Chem 15:17-45

24. Ketchie WC, Murayama M, Davis RJ (2007) Top Catal 44:307-317

25. Zope BN, Hibbitts DD, Neurock M, Davis RJ (2010) Science 330:74-78

26. Prati L, Martra G (1999) Gold Bull 32:96-101

27. Dodekatos G, Abis L, Freakley S, Tüysüz H, Hutchings GJ (2018) ChemCatChem 10:1-10

28. Villa A, Wang D, Su DS, Prati L (2009) ChemCatChem $1: 510-514$

29. Campisi S, Chan-Thaw CE, Wang D, Villa A, Prati L (2016) Catal Today 278:91-96

30. Campisi S, Schiavoni M, Chan-Thaw C, Villa A (2016) Catalysts $6: 185$

31. Yin H, Wang C, Zhu H, Overbury SH, Sun S, Dai S (2008) Chem Commun 36:4357-4359

32. Lopez-Sanchez JA, Dimitratos N, Hammond C, Brett GL, Kesavan L, White S, Miedziak P, Tiruvalam R, Jenkins RL, Carley AF, Knight D, Kiely CJ, Hutchings GJ (2011) Nat Chem 3:551-556

33. Aliaga C, Park JY, Yamada Y, Lee HS, Tsung C-K, Yang P, Somorjai GA (2009) J Phys Chem C 113:6150-6155

34. Dimitratos N, Villa A, Bianchi CL, Prati L, Makkee M (2006) Appl Catal A 311:185-192

35. Prati L, Villa A, Chan-Thaw CE, Arrigo R, Wang D, Su DS (2011) Faraday Discuss 152:353-365

36. Demirel-Gülen S, Lucas M, Claus P (2005) Catal Today 102-103:166-172

37. Abis L, Freakley SJ, Dodekatos G, Morgan D, Sankar M, Dimitratos N, He Q, Kiely C, Hutchings G (2017) Chem Cat Chem 9:2914-2918

38. Demirel S, Lucas M, Wärnå J, Salmi T, Murzin D, Claus P (2007) Top Catal 44:299-305

Publisher's Note Springer Nature remains neutral with regard to jurisdictional claims in published maps and institutional affiliations. 